Original

\title{
Promotion Effect of a Choline-deficient L-amino Acid- defined (CDAA) Diet on Hepatocellular Foci Formation Initiated by Diethylnitrosamine in Fischer 344 Rats
}

\author{
Shun-ichiro Ishii ${ }^{1}$, Katsumi Omachi ${ }^{1}$, Jun-ichi Kashihara ${ }^{1}$, Hideki Tanaka ${ }^{1}$, \\ Nobuaki Ando ${ }^{1}$, Kazuyuki Kimura ${ }^{1}$, Yoshiyasu Kawabata ${ }^{1}$, and Shuichi Hanada ${ }^{1}$ \\ ${ }^{1}$ Safety Evaluation, Drug Development Laboratories, Pharmaceutical Research Division, Welfide Corporation, 214-1, \\ Yamasaki, Fukusaki-cho, Kanzaki-gun, Hyogo 679-2296, Japan
}

\begin{abstract}
The purpose of this study is to determine which combination of choline-deficient L-amino acid-defined (CDAA) diet as an endogenous factor, phenobarbital (PB) as an exogenous factor, and partial hepatectomy (PH), has the most promotive potential on hepatocellular foci formation initiated by diethylnitrosamine (DEN) in Fischer 344 rats. Experimental groups were treated with various combinations of DEN administration, PB administration, PH and CDAA diet. Formation of hepatocellular foci after eight weeks was examined by glutathione S-transferase placental form (GSTP) immunological staining. The focal area was markedly elevated in the CDAA+DEN group in comparison with the CDAA-only group or the CRF-1(basal diet)+DEN group. CDAA diet was shown to have a strong promotion effect on initiated cells by DEN. In the CRF-1+DEN-treated animals, the additional PB and PH treatment elevated the number of small foci, but slightly did the focal area. The effects of the additional PB and PH treatment in the CDAA+DENtreated animals were not clear as they were masked by the strong promotion effect of CDAA diet. These results showed that CDAA diet was more promotive than the $\mathrm{PB}$ and $\mathrm{PH}$ treatment in inducing hepatocellular foci formation initiated by DEN in rats, and the additional PB and PH treatment could not be promotive furthermore in the CDAA+DEN-treated animals. (J Toxicol Pathol 2001; 14: 105-112)
\end{abstract}

Key words: choline-deficient L-amino acid-defined diet, diethylnitrosamine, phenobarbital, partial hepatectomy, glutathione S-transferase placental form, hepatocellular foci

\section{Introduction}

Hepatocarcinogenesis is a multistage process, the stages of initiation, promotion, and progression, and liver tumor is predicted to be induced after a long period of preneoplastic lesions ${ }^{1,2}$. In vivo testing for prediction of hepatocarcinogenic potential of test substance in human using rodents takes a long-term. Medium-term hepatocarcinogenesis bioassay systems in rats employ an initiater such as diethylnitrosamine (DEN), followed by several weeks of exposure of test substance ${ }^{3,4}$. These systems employ hepatocellular enzyme-altered foci caused by test substance as the endpoint marker lesion ${ }^{3,5-7}$. Hepatocellular enzyme-altered foci expresses multiple phenotype and is detectable using immunological staining

Received: 9 November 2000, Accepted: 9 February 2001

Mailing address: Shun-ichiro Ishii, Safety Evaluation, Drug

Development Laboratories, Pharmaceutical Research Division,

Welfide Corporation, 214-1, Yamasaki, Fukusaki-cho, Kanzaki-gun,

Hyogo 679-2296, Japan

TEL: 81-790-22-5700 FAX: 81-790-24-2100

E-mail: shun@welfide.co.jp by $\gamma$-glutamyltranspeptidase $(\gamma$-GTP), gulutathione $S$ transferase placental form (GST-P) and others ${ }^{8-11}$. Partial hepatectomy $(\mathrm{PH})$ is carried out to enhance these initiaters or test substance's effects ${ }^{12-15}$. It has been reported that phenobarbital (PB), a well-known promoter ${ }^{16-19}$, was not carcinogenic but it caused preneoplastic lesion in a two-year feeding study in Fischer 344 rats $^{20}$.

Carcinogen-treated rats fed a choline-deficient (CD) diet induces a preneoplastic lesion ${ }^{21}$. Meanwhile, cholinedeficient L-amino acid-defined (CDAA) diet was developed by replacing the proteins by pure amino acids to give an equivalent amino acid profile. In constant with semipurified $\mathrm{CD}$ diet, CDAA diet has no contamination of carcinogens or choline. Therefore, it is thought that CDAA diet has a stronger effect to induce liver tumor than semipurified CD diet in rats ${ }^{22-24}$, and the effect of CDAA diet is caused entirely by an endogenous mechanism.

The purpose of this study is to determine which combination of CDAA diet as an endogenous factor, PB as an exogenous factor, and $\mathrm{PH}$, has the most promotive potential on hepatocellular foci formation initiated by DEN in Fischer 344 rats. 


\section{Materials and Methods}

\section{Compounds}

Diethylnitrosamine (DEN, Sigma Chemical Co., USA) and phenobarbital (PB, Wako Pure Chemical Industries Ltd., Osaka) were used as an initiater and promoter, respectively. Saline (Otsuka Pharmaceutical Factory, Inc., Tokushima) was used as vehicle for both compounds.

\section{Animals}

The eighty six male 4-week-old Fischer 344 rats used in this study were obtained from Charles River Japan, Inc.(Kanagawa). Grouping of the rats was performed according to the latest body weight. The animals were housed, two/cage in a climate-controlled animal room at temperature of $24 \pm 3^{\circ} \mathrm{C}$, relative humidity of $55 \pm 15 \%$, and ventilation rate of 10-20 times/h with 12-hour illumination, and allowed free access to the prescribed diets in every group and tap water.

\section{Groups and treatment methods}

Experimental design is shown in Fig. 1. To the animals in group 1, only a CRF-1 basal diet (Oriental Yest Co., Ltd., Tokyo) was fed. To the ones in group 2, only a CDAA (Dyets Inc., USA) diet was fed. The CDAA diet, whose composition is shown in Table 1, was fed from the day before the 1st administration day of DEN (day 1) and was stored under refrigeration until use. To the ones in group 3, a CRF-1 basal diet was fed and DEN was treated. The dose of DEN was set at $95 \mathrm{mg} / \mathrm{kg}(2 \mathrm{ml} / \mathrm{kg})$ and rats were intraperitoneally treated once a week for the first three weeks (day 1, 8 and 15). To the ones in group 4, a CDAA diet was fed and DEN was treated. To the ones in group 5, a CRF-1 basal diet was fed and given DEN and PH. In the partial hepatectomy $(\mathrm{PH})$, the left lobe and the right and left sublobes of the median lobe of the liver were excised. PH was carried out on the day before the first administration of PB (day 28). To the ones in group 6, a CRF-1 basal diet was fed and given DEN, PH, and PB. The dose of PB was set at $60 \mathrm{mg} / \mathrm{kg}(2 \mathrm{ml} / \mathrm{kg})$ and rats were intraperitoneally treated three times a week from week 5 (day 29, 32, 34, 36, 39, 41, $43,46,48,50,53$, and 55). To the ones in group 7, a CDAA diet was fed and given DEN and PH. To the ones in group 8 , a CDAA diet was fed and given DEN and PB. To the ones in group 9, a CDAA diet was fed and given DEN, PH, and PB. This experiment was started on 10 April 1997.

\section{Blood chemistry examination}

At autopsy (day 60-63), blood was collected from the ventral aorta and alkaline phosphatase (ALP, p-NPP substrate method $)^{25,26}$, glutamic-oxaloacetic transaminase (GOT, Henry altered method) ${ }^{27}$, glutamic-pyrvic transaminase (GPT, Henry altered method) ${ }^{27}, \gamma$-glutamyl transpeptidase ( $\gamma$-GTP, $\gamma$-Glu-pNA substrate method $)^{28}$, total cholesterol (TCH, CHE-COD-POD method) ${ }^{29}$, triglyceride (TG, LPL-GK-GPO-POD method) ${ }^{30}$, and free fatty acid (FFA, ACS-MK-PK-LDH method) ${ }^{31}$ in serum measured

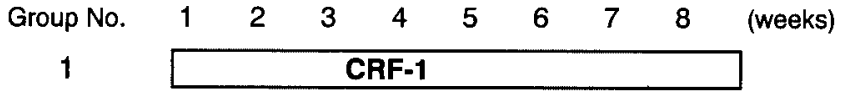

2

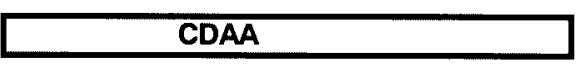

3

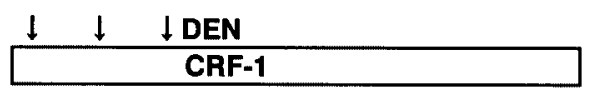

4

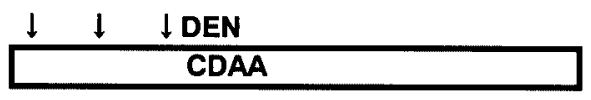

5

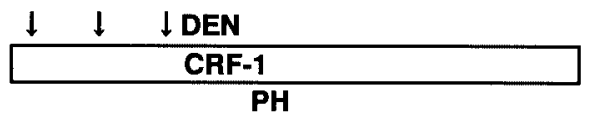

6

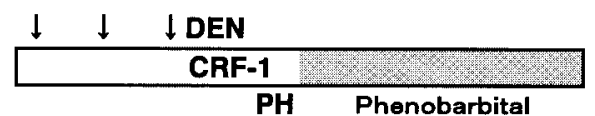

7

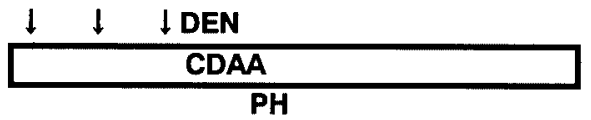

8

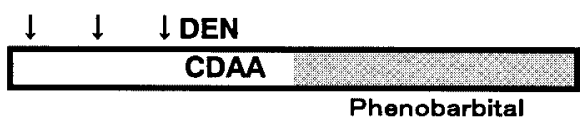

9

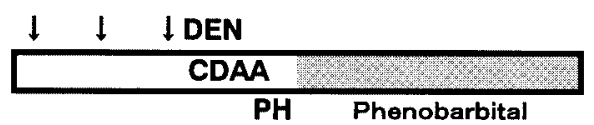

Fig. 1. Experimental design. CDAA was fed from the day before the 1 st administration day of DEN (day 1). DEN was treated at day 1,8 , and 15 . Partial hepatectomy $(\mathrm{PH})$ was carried out at day 28. Phenobarbital (PB) was treated at day 29, 32, 34, 36, $39,41,43,46,48,50,53$, and 55. Autopsy was carried out at day $60-63$.

using an autoanalyzer (AU550, Olympus Optical Co., Ltd., Tokyo).

\section{Pathological examination}

At eight weeks (day 60-63), autopsy was performed after the animals were sacrificed by exsanguination under ether anesthesia. After the liver had been excised and fixed in $10 \%$ neutral buffered formalin fixative, paraffin sections and H.E.-stained specimens were prepared and microscopic examination was carried out.

Immunohistochemical staining using polyclonal antibodies against GST-P was applied to facilitate quantitative evaluation of altered hepatocellular foci. Paraffin sections were stained immunohistochemically using the labeled streptavidin-biotin-peroxidase complex (LSAB) 
Table 1. Compositions of Choline-deficient L-amino aciddefined (CDAA) Diet

\begin{tabular}{lc}
\hline Ingredient & $(\mathrm{g} / \mathrm{kg}$ diet $)$ \\
\hline L-Arginine & 12.7 \\
L-Histidine & 3.4 \\
L-Lysine·HCl & 9.1 \\
L-Tyrosine & 5.7 \\
L-Tryptophan & 1.8 \\
L-Phenylalanien & 7.3 \\
L-Methionine & 1.7 \\
L-Cystien & 3.7 \\
L-Threonine & 4.6 \\
L-Leucine & 10.5 \\
L-Isoleucine & 6.1 \\
L-Valine & 6.3 \\
Glycine & 6.2 \\
L-Proline & 7.6 \\
L-Glutamic acid & 28.9 \\
L-Alanine & 5.1 \\
L-Asparatic acid & 15.8 \\
L-Serine & 7.2 \\
Corn strarch & 100 \\
Dextrin & 100 \\
Cellulose & 50 \\
Sucrose & 406.67 \\
Sodium bicarbonate & 4.3 \\
Corn oil & 50 \\
Primex & 100 \\
Modified AIN-76 salt mix & 35 \\
AIN-76A vitamin mix & 10 \\
Ferric citrate & 0.33 \\
\hline
\end{tabular}

method for binding of rabbit anti-rat GST-Yp polyclonal antibody (1 : 1000 ; BIO PREP, IRELAND). The analytical procedure for the GST-P-stained specimens was as follows. Photographs $(\times 10)$ of GST-P-stained specimens of whole cross-section of liver were taken. Photographs were jointed to construct complete cross-sectional image. GST-Ppositive foci (hereinafter foci) were painted out with felt pen. Cross-sectional images were processed by Image Scanner (GT-6500, SEIKO EPSON Co., Ltd., Nagano) (using EpScan Mac). The area of each focus and total crosssectional area of each image were measured using Adobe Photoshop and NIH image. Number of foci per unit area and focal area per unit area were calculated from data on number of foci, mean focal area, total focal area, and total organ area.

\section{Statistical evaluation}

All examination data were statistically evaluated by F-t test. First, equal dispersion was tested by $\mathrm{F}$ test (significance level 5\%). Student-t test was carried out where population variance was judged to be equal, and Welch-t test where it was judged different. Bilateral significance level was set at $5 \%$ and $1 \%$.

\section{Results}

Survival, final body weight, and liver weight

Survival, final body weight, and liver weight are shown in Table 2. In the CDAA+DEN-treated groups (7 and 9), four animals died after PH. Final body weight was reduced in the CDAA-only group (2) in comparison with the CRF-1only group (1), and was further reduced in the CDAA+DENtreated groups $(4,7,8$, and 9) in comparison with the CDAA-only group (2). Liver weight was markedly elevated in the CDAA-only group (2) in comparison with the CRF-1only group (1), and was further elevated in the CDAA+DEN-treated, but not PH-treated groups (4 and 8 ) in comparison with the CDAA-only group (2).

Autopsy and histopathological findings in liver, and blood chemistry examination

In the CDAA-treated groups $(2,4,7,8$ and 9), a pale enlarged liver with a rough surface was observed in almost all animals. Histopathological findings of H.E.-stained specimens are shown in Table 3. In group 1 (CRF-1), no marked change was observed. Findings in group 2 (CDAA) not observed in group 1 (CRF-1) were fibrosis, severe vacuolar degeneration, oval cell formation, and altered hepatocellular foci. Findings in group 3 (CRF-1+DEN) not observed in group 1 (CRF-1) were slight vacuolar degeneration and altered hepatocellular foci. In group 4 (CDAA+DEN), fibrosis was more marked and oval cells more numerous than in group 2 (CDAA). The altered hepatocellular foci appeared pseudocircular separated by fiber. Almost all animals showed such changes to a severe degree. In group $5(\mathrm{CRF}-1+\mathrm{DEN}+\mathrm{PH})$, altered hepatocellular foci were more marked than in group 3 (CRF$1+\mathrm{DEN})$. Group $6(\mathrm{CRF}-1+\mathrm{DEN}+\mathrm{PH}+\mathrm{PB})$ showed almost the same findings as group 3 (CRF-1+DEN). In group 7 $(\mathrm{CDAA}+\mathrm{DEN}+\mathrm{PH})$, oval cells were slightly more numerous than in group 4 (CDAA+DEN). In groups 8 $(\mathrm{CDAA}+\mathrm{DEN}+\mathrm{PB})$ and $9(\mathrm{CDAA}+\mathrm{DEN}+\mathrm{PH}+\mathrm{PB})$, findings were almost the same as in group 4 (CDAA+DEN).

In blood chemistry examination, in the CDAA-treated groups $(2,4,7,8$, and 9), GOT, GPT, $\gamma$-GTP, and FFA were elevated and TG reduced in comparison with group 1 (CRF1). In the CDAA+DEN-treated groups (4, 7, 8, and 9), $\gamma$ GTP was markedly elevated in comparison with group 2 (CDAA).

\section{Analysis of GST-P-stained specimens}

Figures for focal area are shown in Table 4, and for number of foci by size in Table 5 . In group 1 (CRF-1), no foci were observed. In groups 2 (CDAA) and 3 (CRF$1+$ DEN), foci were observed (Fig. 2a, b). In group 4 (CDAA+DEN), in comparison with group 2 (CDAA), number of foci and focal area were elevated, as did number of foci in all size groups(Fig. 2e). In group 5 (CRF$1+\mathrm{DEN}+\mathrm{PH})$, in comparison with group $3(\mathrm{CRF}-1+\mathrm{DEN})$, focal areas were elevated, as did number of foci of size $0.03-$ $1.0 \mathrm{~mm}^{2}$ (Fig. 2c). In group 6 (CRF-1+DEN+PH+PB), in 
Table 2. Body Weight and Liver Weight

\begin{tabular}{|c|c|c|c|c|c|c|c|c|c|c|c|c|c|c|}
\hline Group & DEN & CDAA & $\mathrm{PH}$ & PB & \multicolumn{2}{|c|}{ Number of animals } & \multicolumn{4}{|c|}{$\begin{array}{l}\text { Body weight (day } 57) \\
(\mathrm{g})\end{array}$} & \multicolumn{4}{|l|}{$\begin{array}{l}\text { Liver weight } \\
\text { (g) }\end{array}$} \\
\hline 1 & - & - & - & - & 10 & 10 & $281.97 \pm 14.09$ & $\mathrm{CT}$ & & & $6.856 \pm 0.440 \mathrm{CT}$ & & & \\
\hline 2 & - & + & - & - & 10 & 10 & $222.86 \pm 9.21$ & $* *$ & $\mathrm{CT}$ & & $11.689 \pm 1.183 * *$ & $\mathrm{CT}$ & & \\
\hline 3 & + & - & - & - & 10 & 10 & $257.52 \pm 5.11$ & $* *$ & & CT & $6.387 \pm 0.226 * *$ & & CT & \\
\hline 4 & + & + & - & - & 10 & 10 & $192.65 \pm 7.62$ & $* *$ & $* *$ & $\mathrm{CT}$ & $13.430 \pm 1.367 * *$ & $* *$ & & CT \\
\hline 5 & + & - & + & - & 4 & 4 & $263.85 \pm 3.96$ & $* *$ & & $*$ & $6.335 \pm 0.234 *$ & & - & \\
\hline 6 & + & - & + & + & 4 & 4 & $247.75 \pm 4.10$ & $* *$ & & $* *$ & $6.225 \pm 0.153 *$ & & - & \\
\hline 7 & + & + & + & - & 14 & $10 \#$ & $169.28 \pm 14.23$ & & $* *$ & $* *$ & $9.449 \pm 2.352$ & $*$ & & $* *$ \\
\hline 8 & + & + & - & + & 10 & 10 & $190.32 \pm 7.21$ & & $* *$ & - & $14.118 \pm 1.370$ & $* *$ & & - \\
\hline 9 & + & + & + & + & 14 & $10 \#$ & $175.32 \pm 12.33$ & & $* *$ & $* *$ & $10.365 \pm 1.011$ & $*$ & & $* *$ \\
\hline
\end{tabular}

DEN: diethylnitrosamine, CDAA: choline deficient L-amino acid defiend diet, PH: partial hepatectomy, PB: phenobarbital, CDAA (-): CRF-1 was fed to animals.

\#: Differences from the start means number of the dead after PH.

$* *, *$ Significantly different from control $(\mathrm{CT})(* *: \mathrm{p}<0.01, *$ : $<<0.05),-$ : Not signficanlty different.

Table 3. Histopathological Findings of Liver

\begin{tabular}{|c|c|c|c|c|c|c|c|c|c|c|}
\hline \multirow[b]{7}{*}{ Findings } & Group & 1 & 2 & 3 & 4 & 5 & 6 & 7 & 8 & 9 \\
\hline & DEN & - & - & + & + & + & + & + & + & + \\
\hline & CDAA & - & + & - & + & - & - & + & + & + \\
\hline & PH & - & - & - & - & + & + & + & - & + \\
\hline & PB & - & - & - & - & - & + & - & + & + \\
\hline & $\mathrm{n}$ & 10 & 10 & 10 & 10 & 4 & 4 & 10 & 10 & 10 \\
\hline & Grade & $\pm+2+3+$ & $\pm+2+3+$ & $\pm+2+3+$ & $\pm+2+3+$ & $\pm+2+3+$ & $\pm+2+3+$ & $\pm+2+3+$ & $\pm+2+3+$ & $\pm+2+3+$ \\
\hline \multicolumn{3}{|c|}{ Fibrosis } & 55 & & 19 & & & 91 & 19 & 10 \\
\hline \multicolumn{3}{|c|}{ Vacuolar degeneration } & 10 & 10 & 10 & 4 & 4 & \multirow{2}{*}{$\begin{array}{lll} & 1 & 9 \\
7 & 3 & \end{array}$} & \multirow[t]{2}{*}{10} & 10 \\
\hline Ovar cell & & & 46 & & 10 & & & & & 10 \\
\hline \multicolumn{3}{|c|}{ Altered hepatocellular foci } & 73 & 28 & 28 & 4 & 31 & 10 & 19 & 10 \\
\hline
\end{tabular}

DEN: diethylnitrosamine, CDAA: choline-deficient L-amino acid-defined diet, PH: partial hepatectomy, PB: phenobarbital, CDAA (-): CRF-1 was fed to animals.

Table 4. Number and Area of GST-P Positive Foci

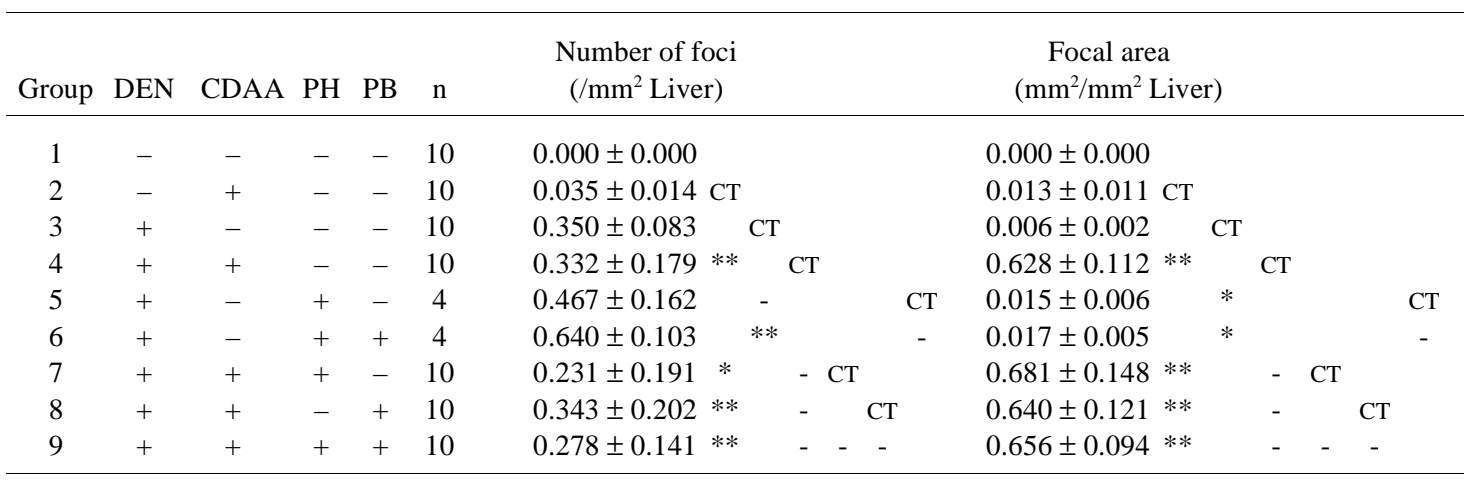

DEN: diethylnitrosamine, CDAA: choline deficient L-amino acid defined diet, PH: partial hepatectomy,

PB: phenobarbital, CDAA (-): CRF-1 was fed to animals.

**, *: Significantly different from control $(\mathrm{CT})(* *$ : $<<0.01, *$ : $\mathrm{p}<0.05),-$ : Not significantly different. 
Table 5. Number of Foci $\left(/ \mathrm{mm}^{2}\right.$ Liver $)$ by Size

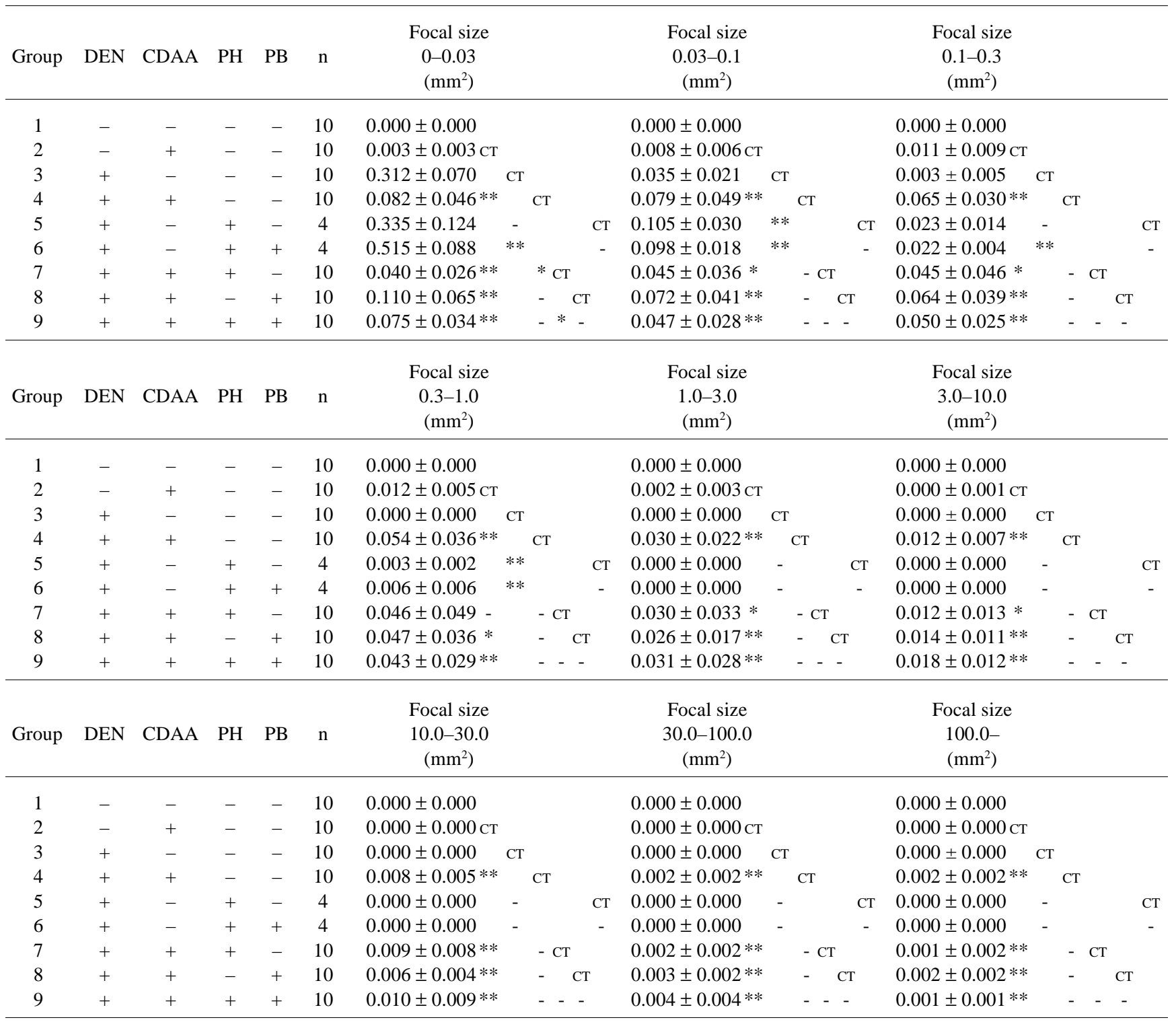

DEN: diethylnitrosamine, CDAA: choline deficient L-amino acid defined diet, PH: partial hepatectomy, PB: phenobarbital, CDAA (-): CRF-1 was fed to animals. **, *: Significantly different from control $(\mathrm{CT})(* *: \mathrm{p}<0.01, *: \mathrm{p}<0.05),-$ : Not significantly different.

comparison with group 3 (CRF-1+DEN), number of foci and focal area were elevated, as did number of foci of size $0-1.0$ $\mathrm{mm}^{2}$ (Fig. 2d). In group 7 (CDAA+DEN+PH), in comparison with group $4(\mathrm{CDAA}+\mathrm{DEN})$, number of foci of size $0-0.03 \mathrm{~mm}^{2}$ was reduced(Fig. 2f). In groups 8 $(\mathrm{CDAA}+\mathrm{DEN}+\mathrm{PB})$ and $9(\mathrm{CDAA}+\mathrm{DEN}+\mathrm{PH}+\mathrm{PB})$, in comparison with group 4 (CDAA+DEN), no change was observed (Fig. 2g, h).

\section{Discussion}

Focal area was markedly elevated in the CDAA+DENtreated group (4) in comparison with the CDAA-only group (2) or the CRF-1+DEN group (3), but was not further elevated in the groups treated with $\mathrm{PH}, \mathrm{PB}$ or $\mathrm{PH}+\mathrm{PB}$ in addition to CDAA+DEN (7, 8, and 9). PB is a well-known exogenous promoter ${ }^{16-19}$. The regeneration of liver after $\mathrm{PH}$ proceeds through compensatory hypertrophy of liver lobes $^{32,33}$ and PH prompts synthesis of DNA in hepatocytes and cell division ${ }^{12-15}$. But the effect of additional $\mathrm{PH}$ and $\mathrm{PB}$ treatment was not clear in the CDAA+DEN-treated groups $(4,7,8$, and 9$)$. These findings were taken as showing that CDAA diet had a strong promotion effect in cells initiated by DEN. In the CDAA+DEN-treated groups (4, 7, 8, and 9), histopathological examination showed marked fibrosis, and blood chemistry examination showed marked elevation of $\gamma$ GTP in comparison with the CDAA-only group (2). The marked fibrosis was thought to be induced by severe hepatocyte necrosis and an indication of strong cytotoxicity by synergistic effects of DEN and CDAA diet. Liver tissue 


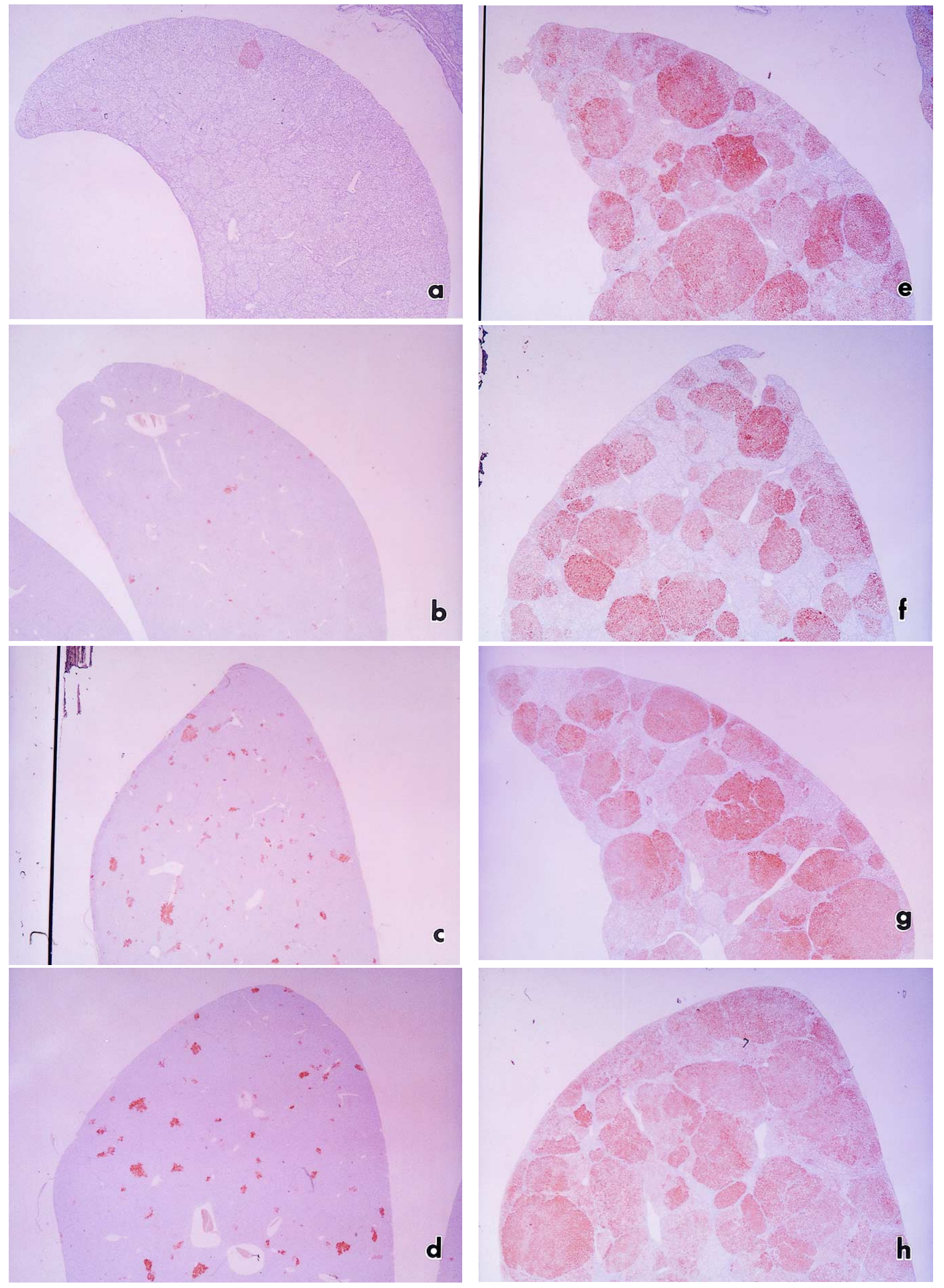


$\gamma$-GTP is known as a marker of hepatocellular enzymealtered foci ${ }^{8-11,34}$. Since a marked increase of GST-Ppositive foci was observed in the CDAA+DEN-treated groups $(4,7,8$, and 9), increase in blood $\gamma$-GTP was thought to be a change related to the formation of hepatocellular enzyme-altered foci. Meanwhile, in the CRF-1+DENtreated animals, the additional $\mathrm{PB}$ and $\mathrm{PH}$ treatment elevated the number of small foci, but slightly did the focal area. Since focal area in the groups treated with $\mathrm{PH}$ or $\mathrm{PH}+\mathrm{PB}$ in addition to CRF-1+DEN $(5,6)$ showed much lower values than in the CDAA+DEN group (4), the promotion effect of $\mathrm{PH}$ and $\mathrm{PB}$ was thought to be much weaker than that of the CDAA diet.

Nowadays, 8-hydroxyguanine (8-OHG) has been a focus of attention as a new marker of carcinogenesis ${ }^{35,36}$. 8$\mathrm{OHG}$ has been reported that to be produced in vitro study when the C-8 position of guanine residues in DNA is hydroxylated by various oxygen radical producing agents ${ }^{37}$. CDAA diet has been reported to induce linear increase in 8OHG in liver cells from the first day of feeding ${ }^{24}$. Therefore, CDAA diet is thought to induce reactive oxygen species (ROS)-derived oxidative stress to rat liver, presumably by inflammatory cells such as Kupffer cells or hepatocytes ${ }^{38}$. $\mathrm{PB}$ also has been reported to produce reactive oxygen ${ }^{39,40}$. Meanwhile, as for DEN used in this study, 8-OHG increases in liver cells several hours after administration of $0.001 \mathrm{mg} /$ $\mathrm{kg}$ of DEN to F344 rats ${ }^{41}$. DEN is thought to be metabolized by $\mathrm{P}-450$ in the liver, where it becomes a kind of cationic carcinogenic activator and damages DNA in the nucleus ${ }^{42}$. 8-OHG formation in the liver DNA by DEN is thought to be involved in initiation by $\mathrm{DEN}^{41}$. In recent years, the relation of hepatocyte necrosis and Ito cells to formation of cirrhosis has become clearer ${ }^{43}$. When hepatocyte necrosis occurs, Ito cell proliferation factor is secreted, and inflammatory cells such as Kupffer cells gather and are activated ${ }^{44,45}$. In the CDAA+DEN-treated groups (4, 7, 8, and 9), inflammatory cells were thought to be strongly activated by severe hepatocyte necrosis, and to produce reactive oxygen further and enhance CDAA diet's promotion effect.

These results showed that CDAA diet was more promotive than the $\mathrm{PB}$ and $\mathrm{PH}$ treatment in inducing hepatocellular foci formation initiated by DEN in rats, and the additional $\mathrm{PB}$ and $\mathrm{PH}$ treatment could not be promotive furthermore in the CDAA+DEN-treated animals.

\section{References}

1. Pitot HC, Dragan YP, Teeguarden J, Hsia S, and Campbell $\mathrm{H}$. Quantitation of multistage carcinogenesis in rat liver. Toxicol Pathol 1996; 24: 119-128.
2. Ledda-Columbano GM, Coni P, Simbula G, Zedda I, and Columbano A. Compensatory regeneration, mitogen-induced liver growth, and multistage chemical carcinogenesis. Environ Health Perspect 1993; 101: 163-168.

3. Ito N, Hasegawa R, Imaida $K$, Hirose $M$, and Shirai $T$. Medium-term liver and multi-organ carcinogenesis bioassays for carcinogens and chemopreventive agents. Exp Toxic Pathol 1996; 43: 113-119.

4. Jauch A and Lutz WK. Metallothionein protein variants generated in rat liver as a result of DNA and RNA ethylations by the carcinogen diethylnitrosamine. Mutat Res 1986; 164: 361-367.

5. Tsuda H, Lee G, and Farber E. Induction of resistant hepatocytes as a new principle for a possible short-term in vivo test for carcinogens. Cancer Res 1980; 40: 1157-1164.

6. Peraino C, Staffeldt EF, and Ludeman VA. Early appearance of histochemically altered hepatocyte foci and liver tumors in female rats treated with carcinogens one day after birth. Carcinogenesis 1981; 2: 463-465.

7. Goldsworthy TL and Pitot HC. An approach to the development of a short-term whole-animal bioassay to distinguish initiating agents (incomplete carcinogens), promoting agents, complete carcinogens, and noncarcinogens in rat liver. J Toxicol Environ Health 1985; 16: $389-402$.

8. Tatematsu M, Mera Y, Ito N, Satoh K, and Sato K. Relative merits of immunohistochemical demonstrations of placental, $\mathrm{A}, \mathrm{B}$ and $\mathrm{C}$ forms of glutathione $\mathrm{S}$-transferase and histochemical demonstration of gamma-glutamyl transferase as markers of altered foci during liver carcinogenesis in rats. Carcinogenesis 1985; 6: 1621-1626.

9. Tsuda H, Hasegawa R, Imaida K, Masui T, Moore MA, and Ito $\mathrm{N}$. Modifying potential of thirty-one chemicals on the short-term development of gamma-glutamyl transpeptidasepositive foci in diethylnitrosamine-initiated rat liver. Gann 1984; 75: 876-883.

10. Konishi Y, Takahashi S, Ohnishi T, Denda A, Mikami S, Emi Y, and Nakae D. Possible role of poly(ADP-ribose) polymerase on the early stage of liver carcinogenesis by diethylnitrosamine in rats. Princess Takamatsu Symp 1983; 13: 309-319.

11. Kitahara A, Satoh K, Nishimura K, Ishikawa T, Ruike K, Sato K, Tsuda H, and Ito N. Changes in molecular forms of rat hepatic glutathione $S$-transferase during chemical hepatocarcinogenesis. Cancer Res 1984; 44: 2698-2703.

12. Yusuf A, Laconi E, Rao PM, Rajalakshmi S, and Sarma DS. The effect of $1 / 3$ partial hepatectomy on the growth of glutathione S-transferase positive foci. Carcinogenesis 1999; 20: $1143-1145$.

13. Hilpert D and Neumann HG. The effects of partial hepatectomy and of promoters on macromolecular binding of trans-4-acetylaminostilbene metabolites in liver and some extrahepatic tissues of rats. Carcinogenesis 1983; 4: 15271533.

Fig. 2. Foci images from liver of F344 rat. GST-P stain. $\times 10$.
(a) CDAA (Group 2)
(b) CRF-1+DEN (Group 3)
(e) CDAA+DEN (Group 4)
(c) $\mathrm{CRF}-1+\mathrm{DEN}+\mathrm{PH}$ (Group 5)
(f) $\mathrm{CDAA}+\mathrm{DEN}+\mathrm{PH}$ (Group 7)
(d) $\mathrm{CRF}-1+\mathrm{DEN}+\mathrm{PH}+\mathrm{PB}$ (Group 6)
(g) CDAA+DEN+PB (Group 8)
(h) $\mathrm{CDAA}+\mathrm{DEN}+\mathrm{PH}+\mathrm{PB}$ (Group 9) 
14. Neal GE and Cabral JR. Effect of partial hepatectomy on the response of rat liver to aflatoxin B1. Cancer Res 1980; 40: 4739-4743.

15. Craddock VM and Frei JV. Induction of liver cell adenomata in the rat by a single treatment with $\mathrm{N}$-methyl-N-nitrosourea given at various times after partial hepatectomy. Br J Cancer 1974; 30: 503-511.

16. Mochizuki Y, Furukawa K, Sawada N, and Gotoh M. Dosedependent enhancing effect of phenobarbital on hepatocarcinogenesis initiated by diethylnitrosamine in the rat. Gann 1981; 72: 170-173.

17. Maekawa A, Onodera H, Ogasawara H, Matsushima Y, Mitsumori K, and Hayashi Y. Threshold dose dependence in phenobarbital promotion of rat hepatocarcinogenesis initiated by diethylnitrosamine. Carcinogenesis 1992; 13: 501-503.

18. Goldsworthy TL, Hanigan MH, and Pitot HC. Models of hepatocarcinogenesis in the rat--contrasts and comparisons. Crit Rev Toxicol 1986; 17: 61-89.

19. Ito N, Imaida K, Hasegawa R, and Tsuda H. Rapid bioassay methods for carcinogens and modifiers of hepatocarcinogenesis. Crit Rev Toxicol 1989; 19: 385-415.

20. Hagiwara A, Miyata E, Tamano S, Sano M, Masuda C, Funae Y, Ito N, Fukushima S, and Shirai T. Noncarcinogenicity, but dose-related increase in preneoplastic hepatocellular lesions, in a two-year feeding study of phenobarbital sodium in male F344 rats. Food Chem Toxicol 1999; 37: 869-879.

21. Sells MA, Katyal SL, Sell S, Shinozuka H, and Lombardi B. Induction of foci of altered, gamma-glutamyltranspeptidasepositive hepatocytes in carcinogen-treated rats fed a cholinedeficient diet. Br J Cancer 1979; 40: 274-283.

22. Nakae D, Yoshiji H, Maruyama H, Kinugasa T, Denda A, and Konishi Y. Production of both 8hydroxydeoxyguanosine in liver DNA and gammaglutamyltransferase-positive hepatocellular lesions in rats given a choline-deficient, L-amino acid-defined diet. Jpn J Cancer Res 1990; 81: 1081-1084.

23. Nakae D, Yoshiji H, Mizumoto Y, Horiguchi K, Shiraiwa K, Tamura K, Denda A, and Konishi Y. High incidence of hepatocellular carcinomas induced by a choline deficient Lamino acid defined diet in rats. Cancer Res 1992; 52: $5042-$ 5045.

24. Nakae D. Endogenous liver carcinogenesis in the rat. Pathol Int 1999; 49: 1028-1042.

25. Roy AV. Rapid method for determining alkaline phosphatase activity in serum with thymolphthalein monophosphate. Clin Chem 1970; 16: 431-436.

26. Bretaudiere JP, Vassault A, Amsellem L, Pourci ML, ThieuPhung $\mathrm{H}$, and Bailly M. Criteria for establishing a standardized method for determining alkaline phosphatase activity in human serum. Clin Chem 1977; 23: 2263-2274.

27. Thefeld W, Hoffmeister H, Busch EW, Koller PU, and Vollmar J. Reference values for the determination of GOT, GPT, and alkaline phosphatase in serum with optimal standard methods. Dtsch Med Wochenschr 1974; 99: 343-344.

28. Szasz G. A kinetic photometric method for serum gammaglutamyl transpeptidase. Clin Chem 1969; 15: 124-136.

29. Allain CC, Poon LS, Chan CS, Richmond W, and Fu PC. Enzymatic determination of total serum cholesterol. Clin Chem 1974; 20: 470-475.

30. Bucolo G and David H. Quantitative determination of serum triglycerides by the use of enzymes. Clin Chem 1973; 19:
476-482.

31. Bar-Tana J, Rose G, and Shapiro B. The purification and properties of microsomal palmitoyl-coenzyme A synthetase. Biochem J 1971; 122: 353-362.

32. Desplaces A, Choppin J, and Saracino RT. Study of the action of bleomycin on compensatory hypertrophy of the mouse liver after partial hepatectomy. C R Acad Sci Hebd Seances Acad Sci D 1972; 274: 1089-1092.

33. Sakamoto T, Liu Z, Murase N, Ezure T, Yokomuro S, Poli $\mathrm{V}$, and Demetris AJ. Mitosis and apoptosis in the liver of interleukin-6-deficient mice after partial hepatectomy. Hepatology 1999; 29: 403-411.

34. Takahashi S, Tsutsumi M, Nakae D, Denda A, Kinugasa T, and Konishi Y. Persistent effect of a low dose of preadministered diethylnitrosamine on the induction of enzyme-altered foci in rat liver. Carcinogenesis 1987; 8: 509-513.

35. Floyd RA. The role of 8-hydroxyguanine in carcinogenesis. Carcinogenesis 1990; 11: 1447-1550.

36. Wang YJ, Ho YS, Lo MJ, and Lin JK. Oxidative modification of DNA bases in rat liver and lung during chemical carcinogenesis and aging. Chem Biol Interact 1995; 94: 135-145.

37. Kasai H, Chung MH, Jones DS, Inoue $\mathrm{H}$, Ishikawa $\mathrm{H}$, Kamiya H, Ohtsuka E, and Nishimura S. 8-Hydroxyguanine, a DNA adduct formed by oxygen radicals: its implication on oxygen radical-involved mutagenesis/carcinogenesis. J Toxicol Sci 1991; 16: 95-105.

38. Keller GA, West MA, Cerra FB, and Simmons RL. Macrophage-mediated modulation of hepatic function in multiple-system failure. J Surg Res 1985; 39: 555-563.

39. Scholz W, Schutze K, Kunz W, and Schwarz M. Phenobarbital enhances the formation of reactive oxygen in neoplastic rat liver nodules. Cancer Res 1990; 50: 70157022.

40. Puntarulo S and Cederbaum AI. Effect of phenobarbital and 3-methylcholanthrene treatment on NADPH- and NADHdependent production of reactive oxygen intermediates by rat liver nuclei. Biochim Biophys Acta 1992; 1116: 17-23.

41. Nakae D, Kobayashi Y, Akai H, Andoh N, Satoh H, Ohashi $\mathrm{K}$, Tsutsumi M, and Konishi Y. Involvement of 8hydroxyguanine formation in the initiation of rat liver carcinogenesis by low dose levels of $\mathrm{N}$-nitrosodiethylamine. Cancer Res 1997; 57: 1281-1287.

42. Ko IY, Park SS, Song BJ, Patten C, Tan YZ, Hah YC, Yang CS, and Gelboin HV. Monoclonal antibodies to ethanolinduced rat liver cytochrome P-450 that metabolizes aniline and nitrosamines. Cancer Res 1987; 47: 3101-3109.

43. Enzan H, Himeno H, Iwamura S, Saibara T, Onishi S, Yamamoto Y, Miyazaki E, and Hara H. Sequential changes in human Ito cells and their relation to postnecrotic liver fibrosis in massive and submassive hepatic necrosis. Virchows Arch 1995; 426: 95-101.

44. Gressner AM, Lotfi S, Gressner G, and Lahme B. Identification and partial characterization of a hepatocytederived factor promoting proliferation of cultured fat-storing cells (parasinusoidal lipocytes). Hepatology 1992; 16: 12501266.

45. Armendariz-Borunda J, Katayama K, and Seyer JM. Transcriptional mechanisms of type I collagen gene expression are differentially regulated by interleukin-1 beta, tumor necrosis factor alpha, and transforming growth factor beta in Ito cells. J Biol Chem 1992; 267: 14316-14321. 